\title{
Measuring Unemployment Durations of Different Types of Workers
}

\author{
Choi, Chang Kon ${ }^{1^{*}}$ \\ ${ }^{1}$ Department of economics, Chonbuk National University \\ 실업지속기간의 측정모형 \\ 최창곤 $^{1^{*}}$ \\ ${ }^{1}$ 전북대학교 경제학부
}

\begin{abstract}
This paper aims to build a model of unemployment duration, in which each type of unemployment duration can be defined as a function of other exogenous variables. Recently, the so-called mismatch in the labor market has become a big issue in most countries. It is very obvious that 'mismatch' is deeply related to the long duration of unemployment status. Two problems may be head and tail of the same coin. Employing a simple analysis of Markov stochastic process, the model of unemployment duration developed here is useful for seeing the effects of shocks on unemployment duration. The model allows us to distinguish the determinants of different kinds of unemployment and to identify the nature of unemployment duration.
\end{abstract}

요 약 실업의 규모는 실업상태에 진입하는 진입률의 크기와 실업상태의 지속기간이라는 두가지 요인에 의하여 결 정된다. 본 연구는 실업의 지속기간을 측정하는 모형을 개발하여 다양한 형태의 실업자들의 실업지속기간을 측정하고 자 한다. 분석결과 신규실업참가자의 실업지속기간과 실직자들의 실업지속기간의 결정요인은 서로 다르다는 것을 보 인다. 모형을 이용하여 최근 대학 졸업자들이 노동시장에 신규로 참여하여 장기간 구직활동을 하는데 그 요인을 설명 한다.

Key Words : Unemployment Duration, Markov Process, Job Search by College Graduates

\section{Introduction}

This paper's goal is to build a model which can be used to understand the issue of unemployment duration better and to apply it to the current problem in labor market. As well known and pointed out by many literatures, there are two types of factors in determining the unemployment level: the size of flow into unemployment and the duration of unemployment spells. Needless to say, unemployment duration is an important determinant of unemployment rate and is very often more important than the individual worker's flowing into and out of unemployment pool. While the importance of understanding the unemployment duration can not be overemphasized, the theoretical and empirical methods which can model the duration, and importantly which can derive it as a function of other observable or measurable variables have not been discussed sufficiently. One familiar way dealing with duration is to use the hazard rate. However, this methodology has been criticized for a long time. Kennan(1985) may be an earlier example pointing out some problems in frequently used duration model using hazard rate. Furthermore, any serious effort has not been put dealing with the problem of distinguishing different types of unemployment, for example, called voluntary and involuntary jobless workers

This paper was supported by research funds of Chonbuk National University in 2011.

*Corresponding Author: Choi, Chang Kon

Tel: +82-63-270-3045 email: ckchoi@jbnu.ac.kr

Received February 6, $2012 \quad$ Revised April 9, 2012 Accepted April 12, 2012 
according to traditional terminology, or job quitter, new and re-entrant and job loser. Here, we avoid the debate about terminology of "Voluntary" and "Involuntary" unemployment. Hayes(2006) argues that all unemployment may be "involuntary" if the definition is re-defined.

Using the simple analysis of Markov stochastic process, this paper aims to build a model of unemployment duration, in which each type of unemployment duration can be measured as a function of other variables. One motive for building a model of unemployment duration is that we need to distinguish the different kinds of unemployment duration, for example, job-loser, job quitter and new entrants to labor market, or voluntary and involuntary unemployment in the old terms. If we can identify different types of unemployment duration and see the relationship between them and different kinds of shock, we can design and implement better policies in dealing with unemployment problem. Other motive to understand what determines the unemployment duration comes from the current issue of mismatch problem in labor market. Recently, the mismatch in labor market has become a big issue in the Korean economy. It is easy to see that the current problem of mismatch in the labor market is deeply related to the unemployment duration and it can get worse as unemployment duration gets longer.

There have been many studies attempting to model unemployment duration (or unemployment) so far, but the methodologies taken by most of them have been quite diverse so that they are not easily summarized. Clark and Summers(1979), Clark(1990), Burdett et. Al (1981), Kiefer(1988), Devine and Kiefer(1991) are early studies to be mentioned, which employ the concepts of transitional probabilities between unemployment, employment and labor market participation decision in terms of Markov process. Valletta(2005) is a recent one about unemployment duration, but not using Markov model. Budd,et all (1988) looks at the effect of exit probability from unemployment on the long-term unemployment, but do not distinguish different kinds of unemployment.

This paper is built as follows. First, in section II, we develop a basic model of labor market in terms of stochastic process and derive reduced forms of duration for voluntary and involuntary unemployment. In section III, we apply the result in section 2 to the current labor issues and show how we can specify and test a hypothesis. Final concluding remark and direction for future study are in section IV.

\section{The Basic Structure of Labor Market}

We assume that the dynamic movement in the labor market can be described by following one representative worker's processes. As mentioned in section1, the earlier study using this methodology is Clark(1990) and Porterba(1990). And the worker's state can be described as a finite Markov stochastic process $\{X t\}$ ( $\mathrm{t}=\mathrm{time})$. $\{X t\}$ has the following five states with positive probabilities. The transition probability matrix is following.

[Table 1] Transition probabilities

\begin{tabular}{|c|c|c|c|c|c|}
\hline \multicolumn{7}{|c|}{ Transition probabilities } \\
\hline & $\mathrm{S}_{1}$ & $\mathrm{~S}_{2}$ & $\mathrm{~S}_{3}$ & $\mathrm{~S}_{4}$ & $\mathrm{~S}_{5}$ \\
\hline $\mathrm{S}_{1}$ & $\mathrm{P}_{11}$ & 0 & $\mathrm{P}_{13}$ & 0 & $\mathrm{P}_{15}$ \\
\hline $\mathrm{S}_{2}$ & $\mathrm{P}_{21}$ & $\mathrm{P}_{22}$ & 0 & $\mathrm{P}_{24}$ & $\mathrm{P}_{25}$ \\
\hline $\mathrm{S}_{3}$ & $\mathrm{P}_{31}$ & & $\mathrm{P}_{33}$ & $\mathrm{P}_{34}$ & $\mathrm{P}_{35}$ \\
\hline $\mathrm{S}_{4}$ & 0 & $\mathrm{P}_{42}$ & $\mathrm{P}_{43}$ & $\mathrm{P}_{44}$ & $\mathrm{P}_{45}$ \\
\hline $\mathrm{S}_{5}$ & 0 & 0 & 0 & 0 & 1 \\
\hline
\end{tabular}

where $P i j$ is the transition probability from state i to j and $S_{i}$ means state i. Explaining each state, state 1; the case where worker leaves the labor market, so becoming non-labor force, state $2:$; the case where worker is fired or is laid off (involuntary job loss), state 3; worker's quit or entrance to labor force(voluntary job loss), state 4 ; he is employed, finally, state 5; the end of world as an absorbing state. It would be useful to explain more about some states. First, worker enter into the state 1 by being with no job and no looking for a job. Secondly, state 3 is basically for the case of voluntary job loss. A worker become "voluntarily unemployed" by stating to look for a job or quitting the current job. It means that following the definition of 'being unemployed' a non-employed worker become unemployed if he or she starts looking for a kob.

The reason for zero probability of $P_{12}, P_{14}, P_{23}$ and $P_{32}$ is obvious from our division of states. And the specification of last row is easily understood since it is an 
absorbing state. Under this specification, we can find the probabilities of interesting events and the duration of states. After we derive those reduced form of solutions, we can use the solutions to analyze the effects of change in the existing structure. For technical method to derive the expected duration for given transition probability, see the books on stochastic modeling.

To begin with, first, we derive the duration of unemployment for the case of job loss by being fired or laid-off. So, the worker is placed in state 2. To derive it, by applying simple analysis of Markov process, we have the following system of equations from which the reduced forms for duration are solved. In the below system of equation, let $D_{i}(2)$ denote the expected duration of worker in state 2 with beginning state i.(Taylor and Karlin(1984))

$D_{1}(2)=P_{11} D_{1}(2)+P_{13} D_{3}(2)+P_{15} D_{5}(2)$

$D_{2}(2)=1+P_{21} D_{1}(2)+P_{22} D_{2}(2)+P_{24} D_{4}(2)+P_{25} D_{5}$

$D_{3}(2)=P_{31} D_{1}(2)+P_{33} D_{3}(2)+P_{34} D_{4}(2)+P_{35} D_{5}(2)$

$D_{4}(2)=P_{42} D_{2}(2)+P_{43} D_{3}(2)+P_{44} D_{4}(2)+P_{45} D_{5}(2)$

$D_{5}(2)=D_{5}(2)$

We have four unknowns in four equations since we can presume that $D_{5}(2)=0$. By solving this system, solutions of each $D_{i}(2)$ are derived. Here we use some simplifying assumption that worker does not go out of labor market $P_{21}=P_{31}=0$. The derivation gets too messy without this assumption. Then, the above system of equations can be made simple and more readable.

First, the simplified system of equations can be solved for $D_{4}(2)$ ( = duration for initially employed worker to be in the status of layoff or job loss) as following,

$$
\begin{aligned}
D_{4}(2) & =\frac{\left(P_{11}-1\right)\left(P_{13}-1\right) P_{42}}{\left(P_{11}-1\right)\left(P_{33}-1\right) P_{24} P_{43}\left(P_{34}+1\right)} \\
& =\frac{P_{42}}{P_{24} P_{43}\left(P_{34}+1\right)}
\end{aligned}
$$

Thus, the duration of involuntary job loser depends on the probabilities of $P_{42}, P_{43}$ and $P_{24}$, which is quite intuitive except for $P_{43}$. And the presence of $P_{43}$ can be understood because of the effect of aggregate shocks.
Secondly, we can derive the duration of unemployment for other group of labor force, which is the entrant or quitting worker: voluntarily unemployed labor resources. In this case, let $D_{i}(3)$ mean duration of worker in state 3 with initial state i. Here, remembering the widely accepted fact that the quitting worker usually find job quickly, we focus primarily on the case of entrance to labor force. In fact, quit may matter more in some case. However, interestingly, the expected duration of quitting worker is $D_{4}(3)=1 /\left(1-P_{33}\right)$. Note this $D_{4}(3)$ has different meaning from the previous $D_{4}(2)$.

Note that this does not mean zero probability of quit as seen in transition matrix. In deriving the expected duration of those workers, the above system can be used with last column replaced with $\left[\begin{array}{llll}0 & 0 & -1 & 0\end{array}\right]^{\prime}$. Here we get

$$
\begin{aligned}
D_{1}(3) & =\frac{P_{13}\left[\left(P_{22}-1\right)\left(P_{44}-1\right)-P_{24} P_{42}\right]}{\left(P_{11}-1\right)\left(P_{33}-1\right) P_{24} P_{43}\left(P_{34}+1\right)} \\
& =\frac{\left(1-P_{11}\right)\left[P_{24}\left(1-P_{44}\right)-P_{24} P_{42}\right]}{\left(P_{11}-1\right)\left(P_{33}-1\right) P_{24} P_{43}\left(P_{34}+1\right)} \\
& =\frac{1}{P_{34}\left(P_{34}+1\right)}
\end{aligned}
$$

where the property of Marchov stochastic process is used with the presumption of $P_{i 5}=0$. The former means that the summation of probabilities in each row equal to 1 and the latter ignoring the possibility for a worker to exit the economy without experiencing unemployment. Thus, the above solution is saying that the expected duration without finding job for voluntarily unemployed worker depends on the probabilities of $P_{34}$, which makes sense from the discussion of the transition probability matrix. This discussion in terms of expected duration can be described in terms of the limiting probability without losing the main point of the argument. These reduced forms of duration in each state is applied to understand one example of the current labor issues in next section.

\section{Applications}

In this section, first, it is shown that the result in the section 2 may be applied to the recent job issue of the 
difficulty faced by college graduates who are new entrant to labor market. This problem is prevalent in most countries worldwide.(See Budd et al(1988)). Secondly, it is shown that the result in this paper could be useful in dealing with unemployment and job shortage problem lasting for more than decades in Korea.

\subsection{Long unemployment duration of new college graduates}

While unemployment problem is an issue for workers of all ages, it is frequently mentioned that it becomes more serious for young college graduates who are new entrants to the labor market. Their starting status can be classified in state 1 in this model. The fact that they have longer duration of unemployment than other types of workers can be stated as following: $D_{1}(3)$ is relatively larger than $D_{4}(2)$. If the above argument is right, thus, we can make a weak version of this hypothesis like following: $D_{1}(3) / D_{4}(2)>\mathrm{c}$, here $\mathrm{c}$ is a positive constant. To make a more readable form of this condition, we use a simple fact from discussion about marginal and conditional distributions. Before doing it, note that our hypothesis can be expressed in the following form:,

$$
\begin{aligned}
& P_{24} P_{43} / P_{42} P_{34}>c, \text { or equivalently, } \\
& P_{24} / P_{42}>c P_{34} / P_{43}
\end{aligned}
$$

One alternative way to build hypothesis may be to assume that the variable 'duration' has some particular distribution, and to compare the means of both variables D1, D4. This method also yields reduced form of hypothesis which is similar to the ours obtained at the end of this subsection.

The above result is interesting and more informative than it looks. That is, new entrant to the labor market may experience a long unemployment duration because of the relative size of four transitional probabilities. New entrant's job search tends to get longer (a) as the job loser (involuntary) gets a higher chance of getting a new job, (b) the more likely the employed workers keep their jobs, (c) the less likely the job quitter gets a job and (d)the less likely the employed worker quits his(her) job. These conditions are quite intuitive and pointing out a common sense that several types of unemployed workers are competing for a job each other. This common sense, however, is rarely mentioned by economists or any policy makers, which mainly comes from congestion effects. The most interesting one out of four conditions is the condition (a) which reflects the recent hiring policy of firms in Korean labor market. Most firms prefer experienced workers.(See Franz(1990)

While not being pursued seriously in length here, we can suggest briefly how to specify an empirically testable model from the one written in terms of transitional probabilities. The motive is that it is not easy to have reliable data for transitional probabilities. In most cases, we need to design and setup a panal data to get those data. To do this, it is enough to recall some elementary statistics. That is, the above inequality describing the unemployment duration of college graduates in their first job search can be simplified using some statistics. Remember that transitional probabilities are conditional probabilities which can be written by using marginal probabilities. For the following notation, $\operatorname{Pr}\left\{X_{t}=i\right\}$ means the probability of worker to be in state $\mathrm{i}$ at time $\mathrm{t}$ and $\operatorname{Pr}\left\{X_{t}=i \mid X_{t}=j\right\}$ is the conditional probability in the usual sense. Since we can have the equality of $\operatorname{Pr}\left\{X_{t}=4, X_{t-1}=2\right\}=\operatorname{Pr}\left\{X_{t}=2, X_{t-1}=4\right\}$, the left side of the condition (3) becomes; $\operatorname{Pr}\left\{X_{t-1}=2\right\} / \operatorname{Pr}\left\{X_{t-1}=4\right\}$. The equality of both probabilities is true if probability space on which $\mathrm{Xt}$ is defined is constant, which means the same Borel field and probability measure. See Chung(2001). Applying similar analysis to the right side of (3), we have $\operatorname{Pr}\left\{X_{t-1}=3\right\} / \operatorname{Pr}\left\{X_{t-1}=4\right\} c$. By arranging both sides, final form of our hypothesis is derived:

$$
\operatorname{Pr}\left\{X_{t-1}=2\right\}>\operatorname{Pr}\left\{X_{t-1}=3\right\} c
$$

With reduced form of hypothesis of (4), these probabilities can be expressed as a function of exogenous variables so that we can apply qualitative choice model: i.e., $\operatorname{Pr}\left\{X_{t-1}=2\right\}=G(Z)$ and $\operatorname{Pr}\left\{X_{t-1}=3\right\}=H(W)$ where $\mathrm{G}$ and $\mathrm{H}$ are functions, $\mathrm{Z}$ and $\mathrm{W}$ are vectors of exogenous variables which are assumed to determine each probability. Then we can have one simple form of testing, 
for which we can specify function $G(Z)$ and $H(W)$ and test it.

As can be seen in Clark(1990), the issue of youth unemployment has been an important problem for a long time. Clark(1990) tried to use the Markov stochastic model to explain the issue, which is simpler than this paper.

\subsection{The effects of different shocks on unemployment duration}

While not being pursued seriously in this paper, the possible extension and application of this paper's outcome is to identify the effects of different kind of shocks on different types of unemployment. The conjecture is that the effect of a shock on unemployment duration depends on the types of unemployment. In the aggregate level of labor market, one can classify most shocks into two types: the aggregate and sectoral shift shocks. Once we distinguish two different kinds of shocks, we can connect the different effect of different shocks on unemployment duration. For example, Lilien(1982) argues that involuntary job loser tends to stay longer as unemployed when they are hit by the latter shock. Recently, De Loo(2000) applies it to the Netherlands.

This argument is much more relevant in terms of recent shock experience to the Korean economy and labor market. As the economy has been moving from industrial structure into digital or information technology-driven one quickly, most economies have been experiencing fundamental sectoral-shift shock. Even after an economy has been transformed into a digital economy, the society has become more dynamic and been changing more quickly than had been in the industrial society. The new products and new technology are being produced continuingly everyday and are replacing the old ones. It means that labor market is subject to continuing sectoral shift shock as well as the aggregate shock to the overall economy.

For example, Korean labor market has been experiencing two kinds of shock during last two decades. One is the change in industrial structure which is from industrial society to so-called digital or IT-driven society, which certainly makes a sectoral-shift one. The other shock was economic crisis which has taken place in 1998, which has had a long-lasting effect on Korean economy. Comparing to the shock by IT, it looks fair to count this shock as an aggregate one. Experiencing these two different shocks, unemployment rate has increased during the last decade by about $2 \%$, which means an increase in the number of the unemployed by about 420,000 . Korean government has tried to reduce unemployment using many labor market and macroeconomic policies. The effect of such policies, however, has not been so effective and not noticeable. The apparent failure of government policies aiming at reducing unemployment rate could be partly due to the wrong understanding about problem. That is, it is not clear which kind of job loss is contributing more to higher unemployment. For example, it may be possible that sector specific shocks are more important as a determinant of composition of aggregate quantity, and in many cases, the changes in composition inversely affect the aggregate quantity, sectoral-shift shocks and variations of composition driven by them. This issues have been discussed extensively in the literature. For reference to studies in this line of research, see Davis(1987a, b). Put differently, it is an interesting and important question to assess how much of unemployment is due to sectoral-shift shock, and how much of that is due to aggregate shock. The formula of unemployment duration in the section 2 can be developed to deal with this issue, where we can see the determinants of unemployment duration. Importantly, in this model, we can identify the two different unemployment durations and see how they are affected by different determinants. Thus, without using flow analysis to make model, the result in this paper helps us understand the stochastic movements in labor markets.

\section{Concluding Remarks}

This paper develops a Markov model of unemployment duration which can be used to identify different kinds of unemployment duration. The model can explain what determines the unemployment duration of different types of workers in terms of transitional probabilities. Using the model, for example, it is shown that the long duration of recent college graduates' job search can be explained by several transitional probabilities, implying some useful 
policy implications. It is also shown that the result in this paper can be extended to understand the effects of different shocks on the unemployment duration. Through this exercise, one can see that we need a synthetic approach as well as direct and naïve ones to tackle the problem. While leaving a serious task of empirical testing the model in the future, this paper shows that different unemployment duration of different types of workers can be simplified into an observable probabilities.

\section{References}

[1] Budd, A., Levine, P., Smith, P., "Unemployment, Vacancies and the Long-Term Unemployed," in: Economic Journal, Vol.98, pp. 1071-1091, 1988.

[2] Burdett, K, Kieffer, N, Mortenson, D, and Neumannm G., "A Markov Model of Employment, unemployment and Labor Force participation: Estimate from the DIME data, Discussion paper, 1981.

[3] Chung, K.L, A Course in Probability Theory, 3rd ed. Academic Press, 2001.

[4] Clark, K.,B "The Dynamics of Youth Unemployment", in Understanding Unemployment by Summers, L. H., The MIT Press, 1990.

[5] Clark, K. B and Summers, L.H., : "Labor Market Dynamics and Unemployment: A Reconsideration", Brookings Paper on Economic Activity 1, 1979, 13-72.

[6] Davis, S. J., "Fluctuations in the Face of Labor Reallocation", Carneigie Rochester Conference Series on Public Policy 27, (Autumn 1987a)

[7] Davis, S. J., "Allocative Disturbances and Specific Capital in Real Business Cycle Theory", American Economic Review Vol 77, No 2, 1987.

[8] De Loo, Ivo, "The Applicability of Sectoral shift hypothesis in the Netherlands", Journal of Applied Economics, Vol III, No.1, p.57-69, 2000.

[9] Devine, T., and Kiefer, N. (1991), Empirical Labor Economics. The Search Approach, OUP, New York

[10] Franz, W., "Hysteresis in Economic Relationships: An Overview," in: W. Franz (ed.), Hysteresis Effects in Economic Models, Physica-Verlag, Heidelberg, pp. 1-17, 1990.

[11] Greene, W., Econometric Analysis, 2nd edition, Macmillan, NewYork, 1993.

[12] Hayes, M.G., "Comment: Lucas on involuntary unemployment", Cambridge Journal of Economics, Mar,
2006.

[13] Kiefer, N., "Economic Duration Data and Hazard Functions," in: Journal of Economic Literature, Vol. 26, pp. 646-679, 1988.

[14] Kennan, John., "The Duration of Strikes in U.S. Manufacturing" Journal of Econometrics 1985.

[15]Lilien, David, "Sectoral Shift and Unemployment", Journal of Political Economy, 1982, Vol.90, No 4.

[16] Porterba, J., M., "Reporting Errors and Labor Market Dynamicss", in Understanding Unemployment by Summers, L. H., The MIT Press, 1990.

[17] Taylor, H. M., and Karlin, S., An Introduction to Stochastic Modelling, Academic Press, 1984.

[18] Valetta, R., "Rising unemployment Duration in United states: Causes and Consequences", FRB of Sanfransisco, 2005.

\section{최 창 곤(Chang-kon Choi)}

[정회원]

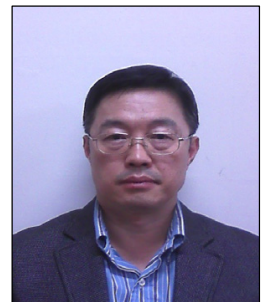

- 1985년 8월 : 전북대학교 대학원 경제학과( 경제학석사)

- 1991년 12월 : 미국 The Univ. of Iowa 대학원 경제학과 (경제 학박사)

- 1993년 10월 현재 : 전북대학 교 경제학과 교수

<관심분야>

노동경제학 거시경제학 